\title{
Silica, silicosis, and progressive systemic sclerosis
}

\author{
GK SLUIS-CREMER, PA HESSEL, EH NIZDO, AR CHURCHILL, AND EA ZEISS
}

From the Epidemiology Research Unit, Medical Bureau for Occupational Diseases, Johannesburg 2000, South Africa

ABSTRACT An inquiry into the relation between exposure to silica dust, the presence of silicosis, and progressive systemic sclerosis was conducted in white South African gold miners by means of a case-control study. Seventy nine cases of progressive systemic sclerosis were matched by year of birth with an equal number of control miners selected randomly but bearing in mind the administrative channel through which the case had come to be identified. Analysis showed no association between silicosis and PSS but did show that the cumulative life time silica exposure was significantly higher in the cases compared with controls. This difference was due to a difference in the intensity of exposure to silica during mining service rather than a difference in duration of service. The results are discussed in the context of current thought on the aetiology of progressive systemic sclerosis, particularly in relation to autoimmune and genetic factors.

Several case reports documenting the co-existence of silicosis and progressive systemic sclerosis (PSS) in the same patient have appeared, mostly from European countries but also from Japan ${ }^{1}$ and the United States. ${ }^{2}$ In some of these cases the diagnosis of PSS was substantiated by a skin biopsy. In 1970 Gunther and Schuchard were able to enumerate 49 such published cases ${ }^{3}$ and since then there have been many more. Devulder et al discussed the association and presented a bibliography up to $1977 .{ }^{4}$ They suggested the eponym "Erasmus syndrome" should be used when referring to the co-existence of silicosis and PSS.

Erasmus, however, did not report primarily on the association of silicosis and PSS. ${ }^{5}$ His study was concerned with the apparently high prevalence of PSS in Witwatersrand gold miners exposed to dust containing a high percentage $( \pm 30 \%)$ of free silica compared with a large male non-mining hospital population which he used as a referent population. In only six of his 17 cases of PSS was definite or probable silicosis considered to be present on chest radiography.

The only other epidemiological study on the association between silicosis and PSS is one by Rodnan et al who noted that of 60 male patients diagnosed as suffering from PSS in the period 1955-6, 26 had been exposed to "prolonged and heavy exposure to silica dust." 2 These cases included 16 coal miners. Coal miners may under certain mining

Received 11 March 1985

Accepted 15 April 1985 conditions be subjected to heavy exposures of siliceous dust but this is unusual. In their report only eight of 19 radiographs available for review showed signs of silicosis. Presumably for seven of the 26 patients no chest radiographs were available.

Both this report and that of Devulder et al, ${ }^{4}$ wh also mention development of PSS in pneumoconiotis. coal miners, leave one uncertain as to the intensity of the exposure to silica (if any) and the nature of the pneumoconiosis that was present.

Certain hitherto unpublished information on the prevalence of scleroderma in South African gold miners is available. ${ }^{6}$ A study was carried out to compare the incidence of PSS among white men over age 19 recognised by the Mines Benefit Society which provides health care to miners (most exposed to silica dust) with that reported to the South African Railways and Harbours Sick Fund, which includes $\frac{\mathbb{}}{3}$ few members exposed to silica dust. During the 10 ; years from 1960 to 1969,29 members of the Mines Benefit Society (7.73/100000 a year) were diagnosed of as having PSS whereas only three of the railway and $₹$ harbour workers $(0.33 / 100000$ a year) developed the 은 disease. Strict criteria for the diagnosis of PSS could not, however, be applied in this study which relied on physicians' private records and memories. Nevertheless, the large difference in the rates is highly $O$ suggestive. The rate for the Railway and Harbour $N$ workers was similar to that reported for white men in Shelby county by Medsger and Masi. ${ }^{\text {? }}$

South African gold miners are exposed to levels of silica dust that may be reasonably accurately

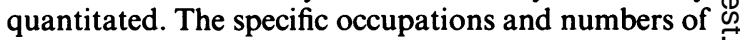
838 
shifts worked are recorded and the silica dust intensities for different occupations have been measured. ${ }^{8}$ The men also have annual chest radiographs and clinical examinations, thereby enhancing the likelihood of discovering silicosis or PSS at onset. Many but not all continue to be examined regularly after ceasing mining. It was considered that these data could be used with confidence to carry out a case-control study to examine the relation between silicosis, exposure to cumulative silica dust, and PSS.

\section{Materials and methods}

A register of cases of PSS seen at the Medical Bureau for Occupational Diseases (MBOD) has been maintained since 1955 . The $\mathrm{MBOD}$ is responsible for monitoring the health of all miners in South frica. A total of 79 definite or probable cases of PSS among white miners according to the criteria of the American Rheumatism Association ${ }^{9}$ had been accumulated by June 1984. Age at onset ranged from 27 to 71 (mean, 45.3). Onset of PSS was deduced from the clinical data recorded in the MBOD files, usually from several successive annual examinations during which symptoms were routinely recorded, and by further questioning of the patients at the time of diagnosis.

Cases were identified in several ways. Some were discovered during routine periodical examinations that are annual statutory examinations performed to renew certificates of fitness for work in the mines. Cases discovered in this way usually did not know that they had PSS before its detection at the periodical examination. The others were identified during benefit examinations which are performed to assess whether the worker is suffering from a compensable disease. Compensable diseases include the pneumoconioses, chronic obstructive airways disease (COAD), PSS, and several other diseases that are associated with exposure to asbestos and are not relevant to this study group which is composed of miners with nearly all of their service in gold mines. Benefit examinations, which are carried out by specialist physicians, are more comprehensive than periodical examinations. They include, for example, an electrocardiograph and lung function tests. Miners apply for benefit examinations if they think that they may be suffering from a compensable disease. They may also request a benefit examination if, having already been compensated, they think that their condition may have worsened to the extent that they are entitled to increased compensation. Whereas there is no minimum service requirement to receive compensation for the pneumoconioses or PSS, long service in dust is required for compensation for COAD, which accounts for $55 \%$ of all compensation decisions. ${ }^{10}$

As a result of the different ways in which the cases were identified and the differences in the miners who undergo periodical compared with benefit examinations (the latter with a high proportion of silicotic patients and those with long service), a scheme was devised for obtaining appropriately matched controls. All controls were selected from miners attending the MBOD for examinations between May 1970 and April 1971 and were randomly matched to cases by year of birth. Cases identified during a periodical examination were matched with controls who had undergone periodical examinations. Cases identified during a benefit examination in whom PSS was discovered as an incidental finding - that is to say, the miner was not appearing for a benefit because he knew that he had PSS - were matched with controls who had undergone benefit examinations. Cases identified during a benefit examination in which PSS was not an incidental finding, the miner appearing for a benefit examination because he knew he had PSS, were matched with controls who had undergone periodical examinations. The reason for distinguishing between the two types of miners who were identified at benefit examinations was that miners in whom PSS was discovered as an incidental finding were thought to be more like others who were attending for benefit examinations with regard to background levels of silicosis and silica dust exposure; the two risk factors of interest. On the other hand, those cases identified during benefit examinations who were attending solely because they knew that they had PSS were thought not to have resembled the remainder of the benefits with regard to background levels of these risk factors. It was thought that a periodical examinee was a more appropriate control for such cases. A further complication resulted from the fact that PSS became a compensable disease in miners in 1974. For this reason, cases with prior knowledge that they had PSS who appeared for benefit examinations before 1974 were matched with controls who had undergone benefit examinations. Through this matching procedure, 46 cases were matched with benefits and 33 were matched with periodicals. This control group will be referred to as the mixed controls.

Despite efforts to determine the circumstances under which each case was diagnosed, it was thought that the use of the mixed controls might underestimate the true associations since some of the subjects in whom PSS was diagnosed as an incidental finding at a benefit examination might actually have appeared for a benefit examination to explore the possibility that they had another compensable disease because they were suffering from disability associated with PSS even though they did not know that they 
had PSS. For this reason, a second control group was selected. These controls were again individually matched by year of birth with the cases and were selected at random from all the miners appearing at the MBOD for either a periodical $(n=29245)$ or a benefit $(n=3876)$ examination between May 1970 and April 1971. It was thought that by increasing the proportion of periodical controls the probable tendency for undiagnosed cases to appear for benefit examinations would be accounted for. This control group will be referred to as the population controls. Results for both control groups will be presented.

For each subject the most recent posteroranterior chest radiograph was read by a single experienced reader for silicosis using the major categories for profusion of rounded opacities of the ILO 1971 classification. ${ }^{11}$ For those whose most recent radiograph showed evidence of silicosis, the year of first appearance of each of the major categories was determined. Also, the year of first appearance of progressive massive fibrosis was recorded if present. As radiographs were usually taken annually at the periodical examinations, the determination of first appearance was thought to be reasonably accurate. All radiograph readings were made without knowledge of the exposure history of the individual or his status as a case or a control. For some case-control pairs, a large difference was found between the dates of the last available radiographs. Typically, the last radiograph of the control was later than that of the case, probably due to the fact that cases often had to leave employment because of disability. For case-control pairs in which only one member showed signs of silicosis and a difference between the dates of the last radiographs was found, films corresponding to the earlier date were read for both members of the pair. In this way the opportunity for development of silicosis was thought to be equal under the null hypothesis of no association between PSS and silicosis.

Information on the amount of time spent in different occupations (most often the number of shifts worked) and the dust levels of these occupations was available for the gold miners. Cumulative silica dust exposure (CDE) to onset of PSS for the cases was calculated by multiplying the number of shifts worked in a given occupation by a weighting factor proportional to the silica dust concentration of that occupation. $^{8}$ The weighting factors were: 12 for $\overline{\bar{a}}$ underground high dust; six for underground 3 moderate dust; three for underground low dust and $\stackrel{\mathbb{Q}}{\stackrel{0}{\circ}}$ all surface dusty occupations; two for occupations on $\ddot{\Rightarrow}$ non-gold, silica containing mines; and one for service $\stackrel{\mathcal{F}}{\stackrel{9}{ }}$ on mines containing little silica, dusty factories and quarries, and non-dusty occupations on gold mines. The weighting factors for non-gold mining service $\frac{\bar{\omega}}{7}$ were based on the available information on the silica $\stackrel{\curvearrowright}{\varrho}$ content of the dusts, mining techniques, and work processes. Whereas the weighting factors for these exposures represent a greater degree of $\circ$ approximation than for the gold mines, little of the $\vec{\omega}$ service recorded for the study subjects was performed ${ }^{\omega}$ outside the large gold mines. In addition to CDE the total number of shifts and the weighted average dust 3 intensity (weighted by the proportion of shifts at each level of intensity) were also compared for cases and $\vec{N}$ controls. CDE, shifts, and average dust intensity for $N$ the controls were calculated up to the date of onset of $\omega_{\infty}$ PSS of the matched cases.

The association between case-control status and the presence of silicosis was evaluated using $\vec{\square}$ McNemar's chi-square test and the exact $95 \% \stackrel{\perp}{\circ}$ confidence interval was determined from the formula $\stackrel{\Phi}{\square}$ of Liddell. ${ }^{12}$ The odds ratio was adjusted for the effects of CDE using conditional logistic regression $\stackrel{\mathbb{}}{-}$ techniques. ${ }^{13}$ Because CDE, shifts, and intensity were $\overrightarrow{0}$ not distributed normally, the Wilcoxon two-sampeo on test $^{14}$ was used to assess differences for these variables.

\section{Results}

Cases and controls did not differ for the presence of silicosis (table 1). The odds ratios did not differ $\overline{\bar{O}}$ significantly from one when either control group was used, either before or after controlling for the effects of $\mathrm{CDE}$. Both the odds ratios were substantially reduced when CDE had been controlled for.

The data in table 2 show that the cases had higher $\stackrel{\mathbb{3}}{3}$ CDE to onset of PSS than the controls, and that this difference was due to higher intensity of exposure rather than to longer duration of service. This was 0 true when either the mixed control group or the population controls were used for comparison, $\bigcirc$ though the differences were more pronounced when $D$ the population controls were used. Within the mixed

Table 1 Matched comparison of cases and controls for silicosis

\begin{tabular}{|c|c|c|c|c|c|}
\hline & & \multicolumn{2}{|c|}{ Mixed controls } & \multicolumn{2}{|c|}{ Population controls } \\
\hline & & $\mathrm{Sil}+$ & Sil- & Sil + & Sil- \\
\hline Cases & $\begin{array}{l}\text { Sil + } \\
\text { Sil - }\end{array}$ & $\begin{array}{l}1 \\
7 \\
\end{array}$ & $\begin{array}{r}9 \\
62 \\
\end{array}$ & $\begin{array}{l}0 \\
4 \\
\end{array}$ & $\begin{array}{l}10 \\
65 \\
\end{array}$ \\
\hline
\end{tabular}

Population controls: Odds ratio $=2 \cdot 50(95 \% \mathrm{CI}: 0 \cdot 72-10 \cdot 95)$, when controlled for CDE, odds ratio $=1 \cdot 18(95 \% \mathrm{CI}: 0 \cdot 26-5 \cdot 38)$. 
Table 2 Comparison of cases and controls for CDE, shifts, and average intensity of exposure

\begin{tabular}{lcc}
\hline & Cases & Controls \\
\hline CDE: & 29727 & \\
Mixed controls: & 25188 & 25030 \\
$\quad$ Periodicals & 32983 & $18472^{*}$ \\
$\quad$ Benefits & 29727 & 29735 \\
Population controls & 5251 & $19817 \dagger$ \\
Shifts: & 4831 & 5204 \\
Mixed controls: & 5552 & 5346 \\
Periodicals & 5251 & 5103 \\
Benefits & 5.63 & 5211 \\
Population controls & 5.31 & $4 \cdot 73^{*}$ \\
Intensity of exposure: & 5.85 & $3.43 \dagger$ \\
Mixed controls: & 5.63 & 5.67 \\
$\quad$ Periodicals & $3.94 \dagger$ \\
Benefits & & \\
Population controls & & \\
\hline
\end{tabular}

For cases and controls, $\mathrm{n}=79$. For mixed controls, $\mathrm{n}$ (periodicals) $=33, \mathrm{n}$ (benefits) $=46$.

${ }^{*} \mathrm{p}<0.05 ; \mathrm{tp}<0.001$.

control group the differences between cases and periodical controls were more pronounced than differences between cases and benefit controls.

CDE up to onset of silicosis for the case and control silicotic subjects was also computed. Exposure was 39909 for the cases, 39077 for the mixed controls $(p=0.82)$, and 45049 for the population controls $(\mathrm{p}=0 \cdot 36)$.

\section{Discussion}

Although the results obtained using the two control groups differed in degree, there was a consistent pattern of higher exposure to dust among the cases with no association with silicosis. Of the two components of dust exposure-intensity and duration-intensity was more important. Given that the results for the two control groups differed by degree for dust exposure, it is reasonable to question which results more accurately represent the true difference. The data in table 2 give some indication that the distinctions made in classifying the cases for the mixed control group were at least partially successful in distinguishing them by mode of presentation. Cases matched with benefit controls had an average CDE of 32983 whereas for those matched to periodical controls the average was 25188 ( $p=0.04)$. It is possible, however, that since miners appearing for benefit examinations generally do so after long careers of working in dust or after initial certification for dust related diseases it may be difficult to discern an effect of CDE or silicosis using benefits as controls. When differences in average intensity of exposure were examined, it was found that for the cases and periodical controls in the mixed control group, the cases had an average intensity 1.54 times that of the controls. The ratio for the population controls was 1.43 . The data for these two comparisons probably reflect the true difference. The comparison using the benefit controls in the mixed control group may not be valid given the high background levels of the risk factors among these controls.

PSS is generally considered to be an autoimmune disease, although other possibilities have been suggested $^{15}$; autoimmune phenomena are generally prominent in PSS, however. Antinuclear antibodies are commonly present and antibodies to Scl-70 antigen, centromere, and nucleolar antigen are specific for PSS. Rheumatoid factor and antismooth muscle antibody may be present and immune complexes and complement may be present in the glomeruli. Abnormalities in $T$ cell numbers (decreased) and function have also been found. The decrease in circulating $T$ cells may be due to their segregation in the sclerodermatous lesions. It has also been suggested that there is an inherited or acquired defect in suppressor $\mathrm{T}$ cell function. ${ }^{16}$

There appear to be associations between silica exposure and other autoimmune diseases. Among these at least six instances of an association with diffuse lupus erythematosus have been described, especially in those subjected to high intensity silica exposure. This disease may have its onset before the development of radiological silicosis. ${ }^{17-20}$

Studies of the immune status have been carried out on subjects who have been exposed to silica and who have developed silicosis. Vigliani and Pernis suggested in 1963 that autoimmune phenomena were involved in the pathogenesis of silicosis. ${ }^{21}$ Depression of $\mathrm{T}$ cell function has also been found in men exposed to silica but without silicosis. ${ }^{20}$ Webster (personal communication) has found a significant occurrence of high titres for rheumatoid factor and antinuclear factors in South African gold miners with long exposure to silica but who had not developed silicosis.

Experimental studies of the immunological effects of silica administered intratracheally or intravenously have shown profound changes in both cellular and humoral immune responses. These include prolongation of skin allograft and bone marrow graft survival and depression of $\mathrm{T}$ cell function. ${ }^{22-24}$

As in many cases of rheumatoid arthritis ${ }^{25}$ and some cases of SLE and PSS, the advent of the autoimmune disease has an unfavourable effect on the progression and severity of the silicosis if present.

Freneaux et al described four cases of silicosis (all of whom had skin histological findings consistent with scleroderma) in whom the onset of scleroderma changed the $x$ ray pattern of silicosis, the nodules becoming blurred and asymmetrical. ${ }^{26}$ In the 10 cases of PSS with silicosis in this study four had atypical features. Two in particular, although regularly examined, showed a sudden, explosive onset of $3 / 3$ profusion of opacities. One had a normal radiograph in 
1971 and a reading of $\mathrm{r} 3 / 3 \mathrm{~A}$ in 1974 . Another had a normal radiograph in 1970 and was read as q3/3 $\mathrm{A}$ in 1976. CDE up to onset of silicosis did not, however, differ significantly between cases and controls-that is, the cases were not more susceptible to silicosis.

Genetic factors have been established in a wide variety of autoimmune diseases; for systemic lupus erythematosus (SLE) concordance for the disease in identical twins is $70 \%$ and another sign of underlying disordered immunoregulation is illustrated by the fact that there is impaired function of suppressor T cells in some blood relations of the cases. There is some degree of linkage of SLE with antigens DR2 and 3. ${ }^{27}$ It could be surmised that the effect of silica on the immune system acts as a trigger to precipitate the autoimmune disease.

PSS appears to be far more common than SLE in those exposed to silica, although SLE is more common in the general population. At least five of the six reported cases of SLE in those exposed to silica were associated with high intensity exposure. Intensity of exposure was also important in our cases of PSS, but the levels were probably far lower than those obtained in the environmental conditions described for the reported cases of SLE. We have no explanation for this.

Instances of familial occurrence of PSS are rare. Soppi et al described an instance of PSS in a sister and a brother and they studied six other siblings in that family. ${ }^{28}$ Of the other siblings, one had antinuclear and anti-DNA antibodies and a positive Rose-Waaler test. One other sister also had antinuclear and antiDNA antibodies. One sibling had slight arthralgia and another, Raynaud's syndrome.

Emerit $e t$ al found an increased prevalence of chromosomal breakages in 29 patients with PSS and in 54 blood relations compared with normal controls. ${ }^{29}$ It is of great interest that 16 of the 54 blood relations he studied reported Raynaud's syndrome and one had Sjögrens syndrome.

No relation with HLA antigens of the A and B locus $^{30}$ or with any DR antigen ${ }^{31}$ has been detected except possibly in the case of the CREST syndrome (increased prevalence of DRW3). ${ }^{32}$ Despite this, one may speculate that there is an underlying genetically determined constitutional diathesis predisposing a person to PSS. Silica may, through its known profound effects on the immune system, precipitate the disease in those predisposed.

In this study an association between PSS and cumulative silica dust dose to onset of PSS was found; the association being primarily due to a difference in the average intensity of exposure. No association was seen between PSS and silicosis per se. Both Erasmus ${ }^{5}$ and Rodnan et $a l^{4}$ found that less than half their cases of PSS who were exposed to silica had in fact con- tracted silicosis (roentgenographically defined). Silica therefore seems to exercise its action in those predis- $\frac{}{2}$ posed to PSS by a mechanism other than is the case in ?. the pathogenesis of silicosis. This is despite the fact that some of the autoimmune phenomena detected in the laboratory are similar in both PSS and silicosis. The fact that intensity of exposure is important suggests that doses of silica high enough to overwhelm the lung associated lymphoid system allow appreciable amounts of silica access to other tissues, especially immunologically active tissues.

\section{References}

${ }^{1}$ Kubo A, Higuchi Y, Miyake Y, Tsunematsu T, Saito T, Inamine M. A case of scleroderma associated with silicosis (abstract). $\mathrm{N}$ Geneva: International Labour Office, 1983:3. (CIS bibliography;
pneumoconiosis; No 19.)

${ }^{2}$ Rodnan GP, Benedek TG, Medsger TA, Cammarata RJ. The association of progressive systemic sclerosis (scleroderma) with coal $\infty$ workers' pneumoconiosis and other forms of silicosis. Ann $ᄋ$ Intern Med 1967;66:323-34.

${ }^{3}$ Gunther G, Schuchard E. Silikose und progressive sklerodermie. Dtsch Med Wochenschr 1970;95:467-8.

${ }^{4}$ Devulder B, Plouvier B, Martin JC, Lenoir L. The association scleroderma-silicosis or Erasmus' syndrome. Nouv Presse Med 1977;6:2877-9.

${ }^{5}$ Erasmus LD. Scleroderma in goldminers on the Witwatersrand with particular reference to pulmonary manifestations. South African Laboratory and Clinical Medicine 1957;3:209-31. \ิ ڤ

${ }^{6}$ Sluis-Cremer GK, Erasmus LD, Hins S, Ludwin SK, Webster $\mathbb{Q}$, Sichel HS. Report on incidence of scleroderma (progressive sys temic sclerosis) in white South African gold miners. Pretorfas Government Printer, 1973. (National Research Institute fơ Occupational Disease report 9/73.)

${ }^{7}$ Medsger TA, Masi AT. Epidemiology of systemic sclerosis (scleroderma). Ann Intern Med 1971;74:714-21.

${ }^{8}$ Beadle DG, Harris E, Sluis-Cremer GK. The relationship between the amount of dust breathed and the incidence of silicosis. In: Shapiro HA, ed. Pneumoconiosis: proceedings of the international conference Johannesburg 1969. London: Oxford University Press, 1970:473-7.

${ }^{9}$ Subcommittee for scleroderma criteria of the American Rheumatism Association Diagnostic and Therapeutic Criteria Committee. Arthritis Rheum 1980;23:581-90.

${ }^{10}$ South African Medical Bureau for Occupational Diseases. Annual report 1982/3. Pretoria: Government Printer, 1983.

${ }^{11}$ International Labour Organisation. International classification of 3 radiographs of pneumoconioses. Geneva: ILO, 1980.

12 Liddell FDK. Simplified exact analysis of case-referent studies: matched pairs, dichotomous exposure. $J$ Epidemiol Community Health 1983;37:82-4.

${ }^{13}$ Breslow NE, Day NE. Statistical methods in cancer research. Vol 1. The analysis of case-control studies. Lyon: IARC, 1980.

${ }^{14}$ Gibbons JD. Nonparametric statistical inference. Tokyo: McGraw- 을 Hill Kogakusha, 1971.

${ }^{15}$ Lee EB, Anhalt GJ, Voorhees JJ, Diaz LA. Pathogenesis of scleroderma. Int J Dermatol 1984;23:85-9.

${ }^{16}$ Postlethwaite AE, Kang AH. Pathogenesis of progressive systemic sclerosis. J Lab Clin Med 1984;103:506-10.

${ }^{17}$ Bernardini P, Iannoconi A. Pulmonary silicosis associated with $\sigma$ systemic lupus erythematosus. Lavoro Umano 1982;30:8-16.

${ }^{18}$ Suratt PM, Winn WC, Brody AR, Bolton WK, Giles RD. Acute silicosis in tombstone sandblasters. Am Rev Respir Dis 1977;115:521-9. 
${ }^{19}$ Bailey WC, Brown M, Buechner HA, Weill H, Ichinose H, Ziskind M. Silico-mycobacterial disease in sandblasters. Am Rev Respir Dis 1974;110:115-25.

${ }^{20}$ Miossec P, Youinou P, Cledes J, et al. Lowered FcIgG receptor bearing $\mathrm{T}$ lymphocytes correlate with non-organ-specific autoantibodies in silicosis. Int Arch Allergy Appl Immunol 1984;73:212-5.

${ }^{21}$ Vigliani EC, Pernis B. Immunological aspects of silicosis. $A d v$ Tuberc Res 1963;12:230-72.

${ }^{22}$ Uber CI, Reynolds RA. Immunotoxicology of silica. CRC Crit Rev Toxicol 1982;10:303-19.

${ }^{23}$ de Shazo RD. Current concepts about the pathogenesis of silicosis and asbestosis. J Allergy Clin Immunol 1982;70:41-9.

${ }^{24}$ Reichrtová E. Macrophage immune function: a screening for silica dust toxicity. In: Proceedings of the VIth International Pneumoconiosis Conference 1984. Vol I. Bochum: BergbauBerfsgenossen, 548-59.

${ }^{25}$ Caplan A. Certain unusual radiological appearances in the chests of coal-miners suffering from rheumatoid arthritis. Thorax 1953;8:29-37.
${ }^{26}$ Fréneaux B, Fréneaux B, Buyse N, Le van Quyen H. Association between silicosis and scleroderma. Nouv Presse Med 1975;4:2087-90.

${ }^{27}$ Schoenfield Y, Schwartz RS. Immunologic and genetic factors in autoimmune disease. $N$ Engl J Med 1984;311:1019-29.

${ }^{28}$ Soppi E, Lehtonen A, Toivanen A. Familial progressive systemic sclerosis (scleroderma): immunological analysis of two patients and six siblings from a single kindred. Clin Exp Immunol 1982;50:275-82.

${ }^{29}$ Emerit I, Housset E, Feingold J. Chromosomal breakage and scleroderma. Studies in family members. J Lab Clin Med 1976;88:81-6.

${ }^{30}$ Májský, Kobiková M, Stava Z. HLA and scleroderma. Tissue Antigens 1979;14:359-60.

${ }^{31}$ Nikš M, Rovensky J, Nyulassy S, Buc M, Stéfanovič J, Zitnan D. Lack of association of HLA-DR antigens with progressive systemic sclerosis (scleroderma). Tissue Antigens 1982;19:238-9.

${ }^{32}$ Germain BF, Espinoza LR, Bergen LL, Vagesh M, Vasey FB. Increased prevalence of DRW3 in the CREST syndrome. Arthritis Rheum 1981;24:857-9.

\section{Vancouver style}

All manuscripts submitted to the $\mathrm{Br} J$ Ind Med should conform to the uniform requirements for manuscripts submitted to biomedical journals (known as the Vancouver style).

The $\mathrm{Br} J$ Ind Med, together with many other international biomedical journals, has agreed to accept articles prepared in accordance with the Vancouver style. The style (described in full in $\mathrm{Br}$ Med J, 24 February 1979, p 532) is intended to standardise requirements for authors.

References should be numbered consecutively in the order in which they are first mentioned in the text by Arabic numerals above the line on each occasion the reference is cited (Manson' confirmed other reports ${ }^{2-5} \ldots$. . In future references to papers submitted to the $\mathrm{Br} J$ Ind Med should include: the names of all authors if there are six or less or, if there are more, the first three followed by $e t$ al; the title of journal articles or book chapters; the titles of journals abbreviated according to the style of Index Medicus; and the first and final page numbers of the article or chapter.

Examples of common forms of references are:

' International Steering Committee of Medical Editors. Uniform requirements for manuscripts submitted to biomedical journals. Br Med J 1979; 1:532-5.

2 Soter NA, Wasserman SI, Austen KF. Cold urticaria: release into the circulation of histamine and eosinophil chemotactic factor of anaphylaxis during cold challenge. $N$ Engl $J$ Med 1976;294:687-90.

${ }^{3}$ Weinstein L, Swartz MN. Pathogenic properties of invading micro-organisms. In: Sodeman WA Jr, Sodeman WA, eds. Pathologic physiology: mechanisms of disease. Philadelphi W B Saunders, 1974:457-72. 